EXTENDED REPORT

\title{
Influence of guideline adherence on outcome in a randomised controlled trial on the efficacy of methotrexate with folate supplementation in rheumatoid arthritis
}

\author{
J Fransen, R F J M Laan, M A F J van der Laar, T W J Huizinga, P L C M van Riel
}

Ann Rheum Dis 2004;63:1222-1226. doi: 10.1136/ard.2003.018861

See end of article for authors' affiliations .....................

Correspondence to: Dr J Fransen, Department of Rheumatology, University Medical Centre Nijmegen, PO Box 9101, 6500 HB Nijmegen, Netherlands; i.fransen@ reuma.umen.nl

Accepted6December 2003

\begin{abstract}
Objective: To study the influence of rheumatologists' adherence to a methotrexate guideline on efficacy and toxicity in the treatment of rheumatoid arthritis.

Methods: In a 48 week randomised controlled trial of methotrexate, comparing folates with placebo, rheumatologists were advised on methotrexate dosage using a guideline reflecting daily practice. The influence of guideline non-adherence on outcome was analysed using generalised estimating equations and survival analysis.

Results: In $51 \%$ of the 411 study patients the guidelines were always followed. Non-adherence resulted in lower doses of methotrexate in $25 \%$ of cases, and higher doses in $24 \%$. The reduction in the disease activity score was significantly greater (mean $-0.4 ; p=0.0085$ ) in the adherent group than in the "low dose" group; the "high dose" group did not differ from the adherent group. Dropout caused by severe adverse events did not differ between the three groups.

Conclusions: There is an indication that adherence to guidelines on methotrexate dosage may benefit patients with rheumatoid arthritis by improving disease activity without increasing toxicity. For definite proof, a randomised controlled trial comparing guideline supported dosing with usual care is needed.
\end{abstract}

$\mathrm{T}$ he most important aim in the treatment of rheumatoid arthritis is the reduction and control of inflammation and the prevention of joint damage. ${ }^{1}$ In general, antirheumatic drug treatment should be used in doses that are sufficiently high to reduce inflammation, unless limiting toxicity is reached. ${ }^{1}$ Methotrexate is regarded as an anchor antirheumatic drug. It acts relatively fast and shows a doseresponse relation. This gives the rheumatologist the opportunity to "titrate" disease modifying antirheumatic drug (DMARD) treatment to control disease activity. ${ }^{2}$ However, in practice it may be difficult to find the optimal effective antirheumatic drug dose for an individual patient. An important reason is the difficulty in assessing rheumatoid inflammation. Thus a combination of standardised systematic evaluation of rheumatoid inflammation and guidelines to assist the clinician's judgment may be helpful in the treatment of patients with rheumatoid arthritis. ${ }^{3}$ The effort involved would be justified if guidelines can be shown to be effective in improving the physician's performance and in leading to an improved health outcome. ${ }^{4}$ In the case of rheumatoid arthritis, we had the opportunity to study the influence of guideline adherence on outcome in a randomised controlled trial reflecting daily practice. ${ }^{5}$ The objective was to study whether rheumatologists' guideline adherence had an influence on the efficacy and toxicity of treatment with methotrexate.

\section{METHODS \\ Design}

The study involved post-hoc analysis of data from a 48 week, multicentre, randomised, double blind, placebo controlled trial (RCT) on the effect of supplementation of folic or folinic acid on the toxicity and efficacy of methotrexate treatment in rheumatoid arthritis. ${ }^{5}$ Eligible patients, who had rheumatoid arthritis according to the ACR criteria, all received methotrexate and were randomly allocated to receive placebo, folic acid, or folinic acid in addition. Rheumatology units from universities as well as general hospitals participated. The same study nurse monitored the patients for adverse events every three weeks. Every six weeks, the patients were additionally monitored for effectiveness and visited their attending rheumatologist. In case of adverse events, visits could be scheduled as needed. Complete information on patients and methods is given in the original publication. ${ }^{5}$ The ethical committees of all participating hospitals approved the study protocol.

\section{Guidelines}

Methotrexate was taken orally once weekly, with a starting dose of $7.5 \mathrm{mg} /$ week and a maximum dose of $25 \mathrm{mg} /$ week. Every six weeks, the dose was increased by $2.5 \mathrm{mg} /$ week until a predefined good response in disease activity was achieved. Disease activity was measured using the disease activity score (DAS). ${ }^{6}$ A good response was defined as a DAS reduction of $\geqslant 1.08$ points (significant change) leading to a current level of DAS $\leqslant 3.2$ (low disease activity). The response criteria were a preliminary version of the EULAR criteria, which require a DAS reduction of $>1.2$ and achievement of low disease activity for a good response.

In the presence of mild adverse events, the methotrexate dose was decreased. In the case of moderate adverse events, the use of methotrexate was temporarily stopped. The occurrence of a severe adverse event led to immediate and definitive cessation of methotrexate (see Van Ede et al for more details). The guidelines were applied by a study coordinator who calculated the DAS and judged efficacy and toxicity on the basis of the results of the monitoring. The attending rheumatologist was advised about the

Abbreviations: ACR, American College of Rheumatology; DAS, disease activity score; DMARD, disease modifying antirheumatic drug; EULAR, European League Against Rheumatism; RAl, Ritchie articular index; RCT, randomised controlled trial; TNF $\alpha$, tumour necrosis factor $\alpha$; VAS, visual analogue scale 
methotrexate dose by phone. This all took place within one week to ensure that dose changes were effective at the patients' next methotrexate intake. However, attending rheumatologists were allowed to deviate from the dose proposed by the guidelines. The methotrexate dose that was finally prescribed was recorded.

\section{Measures}

The DAS was calculated using the Ritchie articular index (RAI), a swollen joint count, erythrocyte sedimentation rate (ESR), and general health. ${ }^{6}$ The RAI was calculated according to the grading and accumulation described by Ritchie et al, and ranged from 0 to $78 .^{8}$ The swollen joint count ranged from 0 to 44. General health (GH) and pain were rated on 100 $\mathrm{mm}$ visual analogue scales (VAS). Patient and physician global disease activity were rated on scales ranging from 0 (no activity) to 5 (very severe activity). The importance of possible adverse events was rated by the patients and used in the calculation of toxicity indices according to Fries and the modification by Felson. ${ }^{10}$

\section{Outcomes}

For this study, the course of the DAS over time was regarded as the primary outcome for efficacy. Primary outcome for toxicity was the occurrence of severe adverse events leading to the definitive cessation of methotrexate. Secondary outcomes were the reduction in the DAS at 48 weeks, the response at 48 weeks, the time needed to reach a good response, the number of observations in good response, trial dropout for any reason, and the toxicity indices at 48 weeks.

\section{Guideline adherence}

The adherence of the rheumatologists to the guidelines was judged after the study had been completed. Adherence was determined from the database, by comparing the prescribed methotrexate dose with the dose proposed by the guidelines. If all methotrexate prescriptions for an individual patient were in congruence with the guidelines, this was determined to be a case of full adherence (FA). A case of non-adherence (NA) was determined if one or more decisions were not in agreement with the guidelines. In case of non-adherence, the dose deviation from the guidelines was calculated. If the dose deviation was positive, the patient was prescribed more methotrexate than the guidelines proposed, and in this case the patient was classified as NAt; if the dose deviation was negative the patient was classified as NA-.

\section{Statistical analysis}

Baseline differences between the three adherence groups (FA, NA-, NA+) were analysed using one way analysis of variance (ANOVA), the Kruskal-Wallis test, or the $\chi^{2}$ test as appropriate. The result of non-adherence to methotrexate dose was analysed by testing the between-group differences of the cumulative dose of methotrexate at 48 weeks, using one way ANOVA and contrasts.

The course of the DAS over time was analysed using a nonlinear regression model with random coefficients for patient, suited for repeated measurements (generalised estimating equations). ${ }^{11}$ Differences between the adherence groups were tested using contrasts. The dropout caused by severe adverse events was analysed using survival analysis, accounting for the time dependent nature of the adherence status. ${ }^{12}$ If that were neglected, it could seem that guideline adherence caused early dropout, whereas in fact early dropout may "cause" adherence by preventing the patient from being involved in non-adherence. Differences in corrected drug survival between the adherence groups were analysed using $\chi^{2}$ tests. $^{12}$

The survival analysis was repeated with dropout for any reason (patient wish, protocol violation, inefficacy, and severe adverse events). Differences between the three adherence groups in DAS reduction and response at 48 weeks, time to good response, number of observations in good response, and toxicity indices were analysed using the $\chi^{2}$ test, one way ANOVA, or Kruskal-Wallis test as appropriate. A Bonferroni procedure was applied when comparing the non-adherence groups with the full adherence group, by dividing $\alpha=0.05$ by 2 , giving a border of statistical significance of 0.025 . The data were analysed using SAS 8.1 (SAS Institute, Cary, North Carolina, USA).

\section{RESULTS}

\section{Guideline adherence}

In $208(51 \%)$ of the 411 patients included in the RCT, all decisions on methotrexate dosage taken by the treating rheumatologist were in agreement with the guideline. In contrast, in 203 patients (49\%) there were 390 decisions that were not in agreement with the guideline. The decisions

\begin{tabular}{|c|c|c|c|}
\hline & \multicolumn{2}{|c|}{ Non-adherence } & \multirow[b]{2}{*}{ Total } \\
\hline & NA- & NA+ & \\
\hline Patients (n) & 102 & 101 & 203 \\
\hline Decisions (n) & 201 & 189 & 390 \\
\hline \multicolumn{4}{|l|}{ Specification of decisions } \\
\hline Restart with less than last tolerated dose & 6 & & 6 \\
\hline Restart with more than last tolerated dose & 3 & 22 & 25 \\
\hline No increase, though not a good response & 132 & 26 & 158 \\
\hline No increase, for other reasons & 15 & 17 & 32 \\
\hline Increased, though good response & 1 & 43 & 44 \\
\hline Increased by $5.0 \mathrm{mg} /$ week & & 15 & 15 \\
\hline Increased by $7.5 \mathrm{mg} /$ week & & 3 & 3 \\
\hline Premature increase & 30 & 45 & 75 \\
\hline Dose above $25 \mathrm{mg} /$ week & & 6 & 6 \\
\hline Decrease below last tolerated dose & 8 & 1 & 9 \\
\hline Decrease too small & & 1 & 1 \\
\hline Decrease by patient initiative & 1 & & $i$ \\
\hline No temporarily halt, though moderate adverse event & & 6 & 6 \\
\hline No decrease, though mild adverse event & 3 & 3 & 6 \\
\hline Unjustified temporarily stop & 2 & & 2 \\
\hline
\end{tabular}


Table 2 Population characteristics at baseline

\begin{tabular}{|c|c|c|c|c|c|}
\hline \multirow[b]{2}{*}{ Variables } & \multicolumn{2}{|l|}{ Non-adherence } & \multirow{2}{*}{$\begin{array}{l}\text { Adherence } \\
\text { FA }\end{array}$} & \multirow[b]{2}{*}{$p$ Value } & \multirow[b]{2}{*}{ Total } \\
\hline & NA- & $\mathrm{NA}+$ & & & \\
\hline $\mathrm{n}$ & 102 & 101 & 208 & \multirow{4}{*}{0.53} & 411 \\
\hline MTX + folinic acid & $41(40 \%)$ & $35(35 \%)$ & $65(31 \%)$ & & $141(34 \%)$ \\
\hline MTX + folic acid & $28(27 \%)$ & 31 (31\%) & $74(36 \%)$ & & $133(32 \%)$ \\
\hline MTX + placebo & $33(32 \%)$ & $35(35 \%)$ & $69(33 \%)$ & & $137(33 \%)$ \\
\hline Female (n) & $62(61 \%)$ & 75 (74\%) & $153(74 \%)$ & 0.04 & 290 (71\%) \\
\hline$R F+(n)$ & $85(88 \%)$ & 78 (80\%) & 155 (78\%) & 0.17 & $318(77 \%)$ \\
\hline Age (years) & 57 (14) & $53(14)$ & 58 (11) & 0.07 & $56(13)$ \\
\hline Disease duration (months) & 47 (12 to 132$)$ & 27 (12 to 72$)$ & 51 (12 to 130$)$ & 0.04 & 45 (12 to 117$)$ \\
\hline Disease activity score & $4.7(1.3)$ & $4.9(0.9)$ & $5.0(1.1)$ & 0.07 & $4.9(1.1)$ \\
\hline Ritchie score & $17(10$ to 26$)$ & $18(12$ to 22$)$ & $19(12$ to 28$)$ & 0.18 & $18(12$ to 26$)$ \\
\hline Swollen joint count & 17 (12 to 22$)$ & $16(11$ to 21$)$ & $17(12$ to 23$)$ & 0.38 & 17 (12 to 22$)$ \\
\hline General health & $47(21)$ & $52(20)$ & 48 (19) & 0.13 & $49(20)$ \\
\hline Pain score & $48(20)$ & 54 (19) & $49(21)$ & 0.14 & $50(20)$ \\
\hline Patient global assessment* & $3(3$ to 4$)$ & $3(3$ to 3$)$ & $3(3$ to 4$)$ & 0.42 & $3(3$ to 4$)$ \\
\hline Physician global assessment† & 3 (3 to 4$)$ & $3(3$ to 4$)$ & $3(3$ to 4$)$ & 0.79 & $3(3$ to 4$)$ \\
\hline \multicolumn{6}{|c|}{$\begin{array}{l}\text { Values are mean (SD) or median (interquartile range). } \\
\text { *Patient's global assessment of disease activity. } \\
\text { †Physician's global assessment of disease activity. } \\
\text { FA, patients with full guideline adherence; MTX, methotrexate; NA-, patients with a net lower methotrexate dose than the guidelines proposed; NAt, patients with } \\
\text { a net higher methotrexate dose than the guidelines proposed. }\end{array}$} \\
\hline
\end{tabular}

involved in non-adherence are listed in table 1 . As a result, individual patients could have received less methotrexate $(\mathrm{NA}-, \mathrm{n}=102)$ or more methotrexate $(\mathrm{NA}+, \mathrm{n}=101)$ than the guideline proposed.

\section{Baseline}

In table 2, we show that both forms of non-adherence (NAand NA+) were equally divided among the three original treatment arms of the trial. At baseline, there were differences in sex (more women in NA+) and disease duration (NA+ shorter). A small and non-significant difference appeared in baseline values of the DAS.

\section{Methotrexate dose}

In fig 1, the deviations of the cumulative methotrexate dose of both NA groups as compared with the FA group are shown. After week 24, the median cumulative dose of the $\mathrm{NA}-$ group did not increase as much as in the NA+ and FA groups. At the end of the trial, the cumulative methotrexate dose of the NA- group (median $615 \mathrm{mg}$ ) was significantly lower $(p=0.007)$ than the cumulative methotrexate dose of the FA group (median $650 \mathrm{mg}$ ). After week 18, the median cumulative methotrexate dose increased in the NA+ group

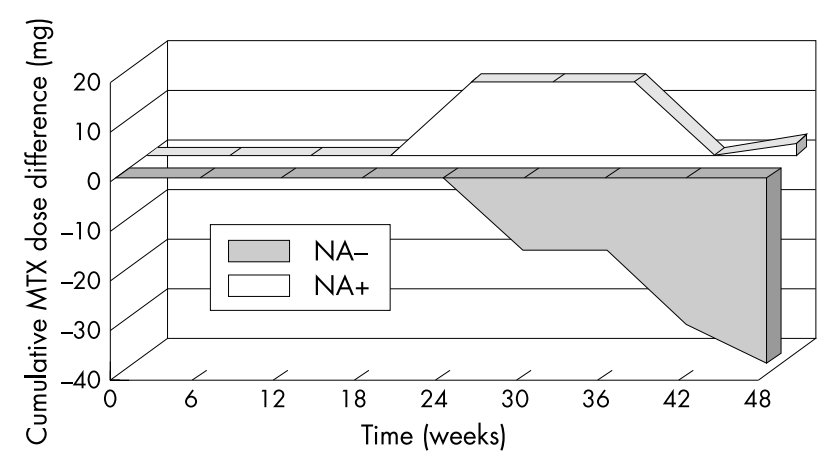

Figure 1 Differences in cumulative methotrexate dose over time. Methotrexate cumulative dose differences are calculated as differences of the non-adherence groups from the full adherence group. Differences are presented as medians. MTX, methotrexate; NA-, patients with a cumulative methotrexate dose at the end of the trial period that was lower than the guidelines proposed; NA+, patients with a cumulative methotrexate dose at the end of the trial period that was higher than the guidelines proposed. compared with the FA group. After week 36 this difference nearly disappeared because of dose increases in the FA group. At week 48, the cumulative dose of the NA+ group (median $652.5 \mathrm{mg})$ was comparable $(\mathrm{p}=0.93)$ with the FA group (median $650 \mathrm{mg}$ ).

\section{Efficacy}

In fig 2, the course of the DAS over time of the three adherence groups is shown. There was a small but significant overall difference in the course of the DAS between the three groups $(p=0.028)$. The NA- group had the lowest mean DAS at the start of the study, but the highest mean DAS at the end. When testing contrasts, the reduction in DAS over time in the NA- group was significantly smaller than in the FA group $(p=0.0085)$, whereas the course of the DAS of the NA+ group did not differ from the FA group $(p=0.64)$. Correction for the level of DAS at baseline did not change the results (not shown). At week 48, the decrease in the DAS was larger in the NAt and FA groups than in the NA- group (table 3). Furthermore, the NA+ and FA groups had a larger fraction of good responders, a shorter time to good response, and more observations in response than the NA- group (table 3).

\section{Toxicity}

The dropout rate caused by severe adverse events was not different between the NA- group and the FA group $\left(\chi^{2}=0.19(\mathrm{ldf}) ; \mathrm{p}>0.60\right)$ or between the NA+ and FA groups $\left(\chi^{2}=0.14(\mathrm{l} \mathrm{df}) ; \mathrm{p}>0.70\right)$. The survival curves are shown in fig 3 . From the curves it can be seen that the dropout in the FA group starts earlier, pointing to the effect of early dropout "causing" adherence, which needed statistical correction in the survival analysis. When analysing dropout for any reason, there were again no significant differences between the adherence groups (not shown). At 48 weeks, no significant differences in the toxicity indices appeared between the three adherence groups (table 3 ).

\section{DISCUSSION}

To our knowledge, this is the first study to show that adherence to guidelines for drug dosing may make a difference in efficacy. According to our results, the prescription of methotrexate doses lower than the guidelines proposed reduced efficacy and had no clear beneficial effect on toxicity. The DAS reduction in favour of guideline 
Table 3 Disease activity and toxicity at week 48

\begin{tabular}{|c|c|c|c|c|c|c|}
\hline & \multirow[b]{2}{*}{ NA- } & \multirow[b]{2}{*}{ FA } & \multirow[b]{2}{*}{$\mathrm{NA}+$} & \multirow[b]{2}{*}{ p Value } & \multicolumn{2}{|l|}{ Contrasts } \\
\hline & & & & & $\mathrm{NA}-v \mathrm{FA}$ & $\mathrm{NA}+v \mathrm{FA}$ \\
\hline $\mathrm{n}$ & 97 & 180 & 98 & & & \\
\hline DAS & $3.2(1.2)$ & $3.2(1.4)$ & $3.1(1.1)$ & 0.61 & - & - \\
\hline Decrease in DAS & $-1.4(1.2)$ & $-1.8(1.3)$ & $-1.8(1.2)$ & 0.05 & 0.020 & 0.80 \\
\hline \multicolumn{7}{|l|}{ DAS response } \\
\hline None & $5(5 \%)$ & $16(8 \%)$ & $4(4 \%)$ & & & \\
\hline Moderate & $57(56 \%)$ & $70(33 \%)$ & $43(42 \%)$ & 0.02 & 0.011 & 0.30 \\
\hline Good & 35 (34\%) & $92(44 \%)$ & $50(49 \%)$ & & & \\
\hline Time to response* (weeks) & $27(12)$ & $24(11)$ & $21(12)$ & 0.0062 & 0.14 & 0.031 \\
\hline Observations in response* $(n)$ & $2(1$ to 4$)$ & $4(2$ to 5$)$ & $4(2$ to 6$)$ & 0.0003 & 0.0003 & 0.57 \\
\hline Toxicity index, Fries & $10.9(4.3$ to 20.4$)$ & 8.8 (2.4 to 19.2$)$ & $11.4(5.3$ to 19.6$)$ & 0.30 & - & - \\
\hline Toxicity index, Felson & 15.4 (13.4 to 20.7$)$ & 10.9 (4.2 to 22.2 ) & $12.9(7.2$ to 22.3$)$ & 0.47 & - & - \\
\hline
\end{tabular}

Values are counts (column percentage), mean (SD), or median (interquartile range).

*Good or moderate response.

DAS, disease activity score; FA, patients with full guideline adherence; NA-, patients with a net lower methotrexate dose than the guidelines proposed; NAt, patients with a net higher methotrexate dose than the guidelines proposed.

adherence was small, but large enough to translate into a shorter time to response and more patients being good responders. The effect of prescribing higher doses than the guidelines proposed did not seem to be more beneficial than full adherence to the guidelines, presumably because the resulting cumulative methotrexate doses were comparable. Thus, in the case of guidelines using the DAS for methotrexate dosing in rheumatoid arthritis, strict adherence to the guidelines appears to be unproblematic and moreover more beneficial than the use of a more loosely "individualised" guideline interpretation. As it can be expected that variation in prescribing methotrexate dose in daily clinical practice is much larger than in this study, clinical guidelines that are sufficiently adhered to may have a greater influence on efficacy, and perhaps on toxicity, in daily clinical practice.

In the original trial, no significant differences in the course of the DAS between the three treatment arms were found. ${ }^{5}$ It is important to note that adherence to the guidelines was equally divided among the three original trial arms. Also, the rheumatologists were allowed to deviate from the guideline for methotrexate dosing. Thus we feel there is no indication that the results were biased by systematic differences in study medication or false records of dosage. The guidelines were derived in a consensus procedure involving key persons from participating centres. Among these there were no rheumatologists or centres that showed a tendency to greater non-adherence than the others (not shown). The most frequent reasons for deviating from the guidelines were the wishes of the patient, a desire to prevent possible adverse reactions, or the wish to induce a response more rapidly. As it was the aim of the original trial to achieve optimal guideline adherence, the differences in methotrexate dose between the three adherence groups were not very large. This means that large differences in outcome between adherence groups

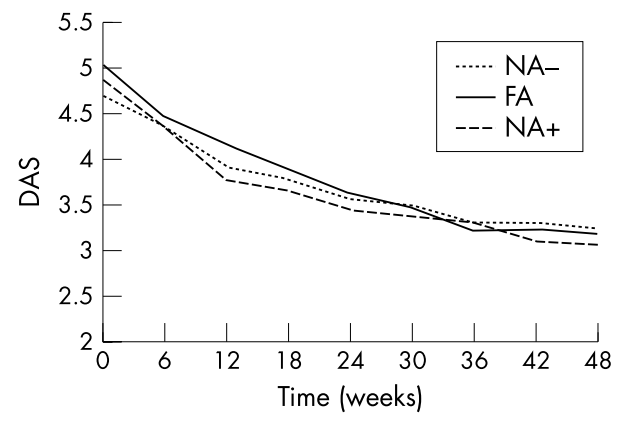

Figure 2 Course of disease activity score (DAS) over time.

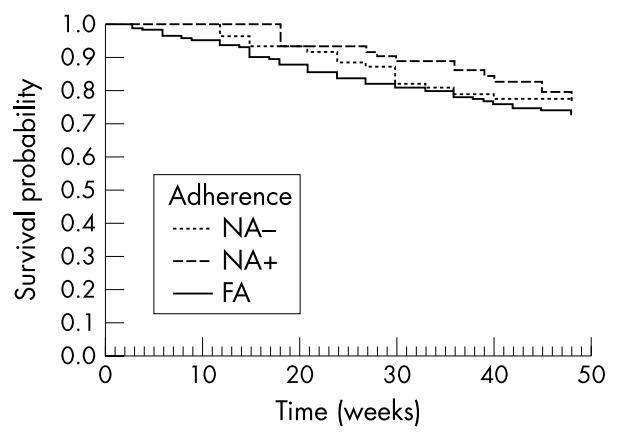

Figure 3 Survival analysis: dropout caused by severe adverse events. $\mathrm{FA}$, patients with full guideline adherence; NA-, patients with a net lower methotrexate dose than the guidelines proposed; $\mathrm{NA}+$, patients with a net higher methotrexate dose than the guidelines proposed.

cannot be expected. No significant difference in toxicity was found, which may also reflect the limited sample size.

The main limitation of this study, however, is that patients were not randomised to either the use of guidelines or usual care. The problem with non-randomisation in any clinical trial is that confounding by indication may occur. For this study, it is therefore not certain what toxicity or efficacy would have been reached in the NA- group had full guideline adherence been applied. Further, variations in guideline use were studied, rather than guideline use versus no use of guidelines. Thus, to be able to answer the question of whether clinical guidelines on drug dosage can indeed be used to improve physician's performance and the health outcome in rheumatoid patients, it is necessary to use an RCT design, comparing the use of clinical guidelines with "usual care".

It should be noted here that clinical guidelines are not intended to replace clinical judgment, and also do not necessarily describe the only way in which a patient can be treated. ${ }^{3}$ However, the contribution of guidelines to clinical practice is that they provide an analytical framework for evaluation and treatment. ${ }^{3}$ The main difficulties in performing an RCT on clinical guidelines are that guidelines are intended to change physicians' performance, while behaviour is generally difficult to change, ${ }^{13}$ and that guidelines are directed at the physician, while relevant effects are expected at the patient level. Perhaps because of these difficulties, there is to date not much evidence that guidelines on drug prescription can change physicians' behaviour and consequently influence health outcomes. ${ }^{14-22}$ In rheumatoid arthritis, there has been limited evidence available until now. In a 
follow up study of a cohort of rheumatoid patients on anti$\mathrm{TNF} \alpha$, the advantages of tailoring anti-TNF $\alpha$ treatment compared with the "one size fits all" dosing scheme were demonstrated using a step-down protocol. ${ }^{23}$ It was shown that the total amount of anti-TNF $\alpha$ given could be reduced by $67 \%$, while the level of disease activity was maintained and no patients dropped out because of persistent worsening of disease activity.

For use in daily clinical practice, a monitoring system has been developed for rheumatoid arthritis. ${ }^{24}$ This allows the systematic recording and (graphical) representation of several indices of disease activity, disability, and joint damage, together with data on drug treatment. The course of disease activity over time can be followed and compared with guidelines or another external reference. How the DAS can be used for the titration of DMARD dose in the suppression of disease activity in individual patients in daily clinical practice is explained by Van Riel and Schumacher. ${ }^{25}$

Taking into account the limitations of this study, our data indicate that adherence to a guideline on methotrexate dosage may benefit rheumatoid patients by improving disease control without increased toxicity. However, definite proof of the clinical value of these guidelines requires a randomised controlled trial comparing guideline supported dosing with usual care.

\section{ACKNOWLEDGEMENTS}

The RCT on the effect of folic or folinic supplementation on the toxicity and efficacy of methotrexate in rheumatoid arthritis was funded by Ontwikkelingsgeneeskunde, Ziekenfondsraad, Netherlands (grant number 95-016). We wish to thank Erik Brummelkamp for his assistance in handling the database.

\section{Authors' affiliations}

J Fransen, R F J M Laan, P L C M van Riel, Department of Rheumatology, University Medical Centre Nijmegen, Nijmegen, Netherlands M A F J van der Laar, Department of Rheumatology, Medisch Spectrum Twente, Enschede, Netherlands

T W J Huizinga, Leiden University Medical Centre, Leiden, Netherlands

\section{REFERENCES}

1 Wolfe F, Cush JJ, O'Dell JR, Kavanaugh A, Kremer JM, Lane NE, et al. Consensus recommendations for the assessment and treatment of rheumatoid arthritis. J Rheumatol 2001;28:1423-30.

2 Van Gestel AM, Van Riel PLCM. Evaluation of early rheumatoid arthritis disease activity and outcome. Baillieres Clin Rheumatol 1997:11:49-63.

3 Scott DL. Clinical guidelines for management. Baillieres Clin Rheumatol 1997; 11:157-79.

4 Cibere J, Sibley JT, Haga M. Rheumatologists' adherence to guidelines for misoprostol use in patients at high risk for nonsteroidal antiinflammatory drug gastropathy. J Rheumatol 2002;29:339-46.

5 Van Ede EA, Laan RFJM, Rood MJ, Huizinga TWJ, Van de Laar MAFJ, Van Denderen CJ, et al. Effect of folic or folinic supplementation on the toxicity and efficacy of methotrexate in rheumatoid arthritis. A forty-eight-week, multicenter, randomized, double-blind, placebo-controlled study. Arthritis Rheum 2001 :44:1515-24.

6 Van der Heijde DMFM, Van 't Hof MA, Van Riel PLCM, Van de Putte LBA. Development of a disease activity score based on judgement in clinical practice by rheumatologists. J Rheumatol 1993;20:579-81.

7 Van Gestel AM, Prevoo MLL, Van 't Hof MA, Van Rijswijk MH, Van de Putte LBA, Van Riel PLCM. Development and validation of the European League Against Rheumatism response criteria for rheumatoid arthritis. Comparison with the preliminary American College of Rheumatology and the World Health Organisation/International League Against Rheumatism criteria. Arthritis Rheum 1996;39:34-40.

8 Ritchie DM, Boyle JA, Mclnnes JM, Jasani MK, Dalakos TG, Grieveson P, et al. Q J Med 1968:37:393-406.

9 Fries JF, Spitz PW, Williams CA, Bloch DA, Sing G, Hubert HB. A toxicity index for comparison of side effects among different drugs. Arthritis Rheum 1990;33:121-30.

10 Felson DT, Anderson JJ, Meenan RF. Use of short-term efficacy/toxicity tradeoffs to select second-line drugs in rheumatoid arthritis. A meta-analysis of published clinical trials. Arthritis Rheum 1992;35:1117-25.

11 Verbeke G, Molenberghs G. Linear mixed models in practice. A SAS-oriented approach. New York: Springer Verlag, 1997.

12 Simon R, Makuch RW. A non-parametric graphical representation of the relationship between survival and the occurrence of an event: application to responder versus non-responder bias. Stat Med 1984;3:35-44.

13 Cabana MD, Rushton JL, Rush AJ. Implementing practice guidelines for depression: Applying a new framework to an old problem. Gen Hosp Psychiatry 2002;24:35-42.

14 Fitzmaurice DA, Hobbs FD, Delaney BC, Wilson S, McManus R. Review of computerized decision support systems for oral anticoagulation management. $\mathrm{Br} J$ Haematol 1998; 102:907-9.

15 Fitzmaurice DA, Hobbs FD, Murray ET, Bradley CP, Holder R. Evaluation of computerized decision support for oral anticoagulation management based in primary care. Br J Gen Pract 1996;46:533-5.

16 Johnston ME, Langton KB, Haynes B, Mathieu A. Effects of computer-based clinical decision support systems on clinician performance and patient outcome. A critical appraisal of research. Ann Intern Med 1994;120:135-42.

17 Hunt DL, Haynes B, Hanna SE, Smith K. Effects of computer-based clinical decision support systems on physician performance and patient outcomes. JAMA 1998;280:1339-46.

18 Vadher B, Patterson DL, Leaning M. Evaluation of a decision support system for initiation and control of oral anticoagulation in a randomised trial. $B M J$ 1997;314:1252-6

19 Hetlevik I, Holmen J, Kruger O. Implementing clinical guidelines in the treatment of hypertension in general practice. Scand J Prim Health Care 1999;17:35-40.

20 Montgomery AA, Fahey T. A systematic review of the use of computers in the management of hypertension. J Epidemiol Community Health 1998;52:520-5.

21 Montgomery AA, Fahey T, Peters TJ, Maclntosh C, Sharp DJ. Evaluation of computer based clinical decision support system and risk chart for management of hypertension in primary care: randomised controlled trial. BMJ 2000;320:686-90.

22 Hetlevik I, Holmen J, Kruger O, Kristensen P, Iversen H, Furuseth K. Implementing clinical guidelines in the treatment of diabetes mellitus in general practice. Int J Technol Assess Health Care 2000;16:210-27.

23 Den Broeder AA, Creemers MCW, Van Gestel AM, Van Riel PLCM. Dose titration using the disease activity score (DAS28) in rheumatoid arthritis patients treated with anti-TNF $\alpha$. Rheumatology (Oxford) 2002;41:638-42.

24 Uitz E, Fransen J, Langenegger T, Stucki G. Clinical quality management in rheumatoid arthritis: putting theory into practice. Swiss Clinical Quality Management in Rheumatoid Arthritis. Rheumatology (Oxford) 2000;39:542-9.

25 Van Riel PLCM, Schumacher HR. How does one assess early rheumatoid arthritis in daily clinical practice? Best Pract Res Clin Rheumatol $2001 ; 15: 67-76$. 